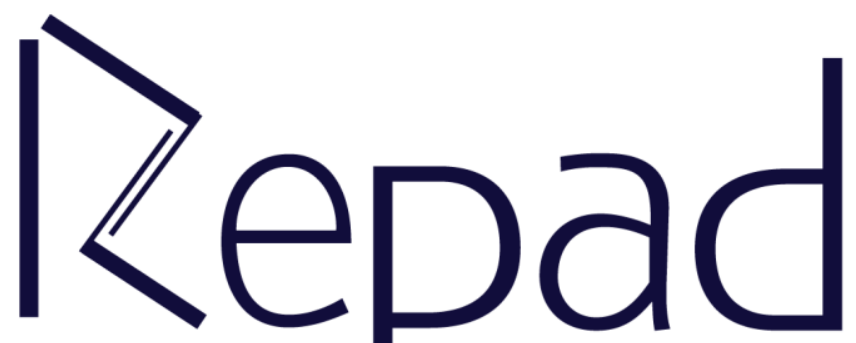

Revista Estudos e

Pesquisas em Administração 


\title{
SOBRE A RELAÇÃO ENTRE AUTO EMPREGO E MULHERES CHEFES DE FAMÍLIA: UMA REVISÃO SISTEMÁTICA
}

\author{
André Luís Ribeiro Lacerda \\ http://orcid.org/0000-0002-6145-4810 \\ ribeirolacerda66@gmail.com \\ Universidade Federal de Mato Grosso \\ Cuiabá, Mato Grosso, Brasil \\ Patricia Cristiane de Souza \\ http://orcid.org/0000-0003-4385-3751 \\ Universidade Federal de Mato Grosso \\ Cuiabá, Mato Grosso, Brasil
}

\section{Resumo}

O conceito de auto emprego tem aparecido vinculado à condição das mulheres chefes de família e tem, muitas vezes, significado intercambiável ao de empreendedorismo. Esta pesquisa investigou a relação entre mulheres chefes de família e auto emprego nas ciências sociais, um desafio que enfrentou o problema de identificar artigos que relacionam o conceito de auto emprego e o de empreendedorismo. Duas hipóteses defendem que o conceito de auto emprego tende a aparecer com mais regularidade nas áreas de psicologia social e sociologia enquanto o de empreendedorismo tende a ser encontrado mais na área da administração. A metodologia usada foi o processo de revisão sistemática. A partir de seis strings de busca 640 artigos foram encontrados e em um estágio de cinco etapas de avaliação, trinta e cinco artigos foram selecionados. Eles permitem sustentar a hipótese principal. Mas a ideia de que os conceitos de empreendedorismo e auto emprego não estariam interligados foi considerada muito genérica visto que alguns artigos consideram empreendedorismo e auto emprego como conceitos afins; em outros o conceito de auto emprego engloba o de empreendedorismo e em outros ainda ocorre o contrário. Uma análise de conteúdo pode ajudar a refinar os conceitos em trabalhos futuros.

Palavras-chave: auto emprego; empreendedorismo; mulher chefe de família.

\section{ON THE RELATIONSHIP BETWEEN SELF EMPLOYMENT AND WOMEN HEADS OF FAMILY: A systematic review}

\begin{abstract}
The concept of self-employment has appeared linked to the condition of female heads of household and often has interchangeable meaning with that of entrepreneurship. This research investigated the relationship between women who head families and selfemployment in the social sciences, a challenge that faced the problem of identifying articles that relate the concept of self-employment to entrepreneurship. Two hypotheses defend that the concept of self-employment tends to appear more regularly in the areas of social psychology and sociology while the concept of entrepreneurship tends to be more frequently found in the area of administration. A systematic review was performed as the research methodology. From six search strings, 640 articles were found and after a fivestage evaluation, thirty-five articles were selected; they all sustained the main hypothesis. But the idea that the concepts of self-employment and entrepreneurship would not be
\end{abstract}


interconnected was considered too general as some articles consider them as related concepts; in others the concept of self-employment encompasses that of entrepreneurship and in others the opposite is true. Content analysis can help refine concepts in future work.

Keywords: self-employment; entrepreneurship; female head of family.

Submetido: 04/01/2020

Aceito: 22/01/2020

Publicado: 31/01/2020

\section{Considerações Iniciais}

O debate sobre a crise de emprego e desemprego data dos anos de 1980. E como mostrou Kalleberg (2000), propostas de criação do próprio emprego e o empreendedorismo têm estado presentes nas páginas de vários documentos da política europeia. Ou seja, já nos anos de 1980, as potencialidades que a criação do próprio emprego poderia ter enquanto medida para combater o desemprego e as precariedades associadas ao emprego padrão eram discutidas. E as ideias de auto emprego e empreendedorismo aparecem como possíveis alternativas. Mas, que significados têm as ideias de auto emprego e empreendedorismo enquanto alternativas ao emprego padrão?

Enquanto conceitos, auto emprego e empreendedorismo aparecem na literatura sociológica, da psicologia social, economia e administração com regularidades variáveis. E, muitas vezes, com significados diferentes. Consultas rápidas em base dados da sociologia (PROQUEST), administração (SCOPUS) e psicologia social (JSTOR) sugerem que o conceito de empreendedorismo aparece mais vezes do que o conceito de auto emprego e que auto emprego, mais do que empreendedorismo, aparece atrelado à condição da mulher chefe de família em algumas disciplinas mais do que em outras.

Por exemplo, na literatura sociológica e econômica o conceito de auto emprego aparece com muita regularidade vinculado à condição das mulheres chefes de famílias. Isto não sugere necessariamente uma associação entre as duas condições, mas uma pesquisa sistemática poderia esclarecer se esta associação tem a ver com certas perspectivas teóricas ou se é uma manifestação representativa das disciplinas. Como podemos entender essa associação? O crescimento da participação da mulher no mercado de trabalho tem provocado transformações na estrutura social do mercado de trabalho (temos a entrada de um novo ator social) e na estrutura social da família e isso parece ter relação com as mudanças que tem ocorrido no emprego padrão e suas possíveis alternativas.

A maior participação das mulheres no mercado de trabalho tem alterado a composição sexual das ocupações e criado uma agenda política que defende, entre outras coisas, a busca de igualdades entre os sexos e mais espaço para as mulheres no sistema de decisão, por exemplo.

$\mathrm{Na}$ estrutura social da família, a mulher não atua mais exclusivamente no espaço doméstico, passou a ter renda e, em uma proporção significativa, passou a ser a chefe de família, conforme dados expostos em Cavenaghi e Alves (2018). Ao mesmo tempo, outros dados mostram que têm aumentado o contingente de mulheres empreendedoras (GEM, 2015; IBQP-SEBRAE-UFPR, 2018), o que é compatível com o crescimento da participação das mulheres no mercado de trabalho. 
O Global Entrepreneurship Monitor (GEM) é hoje considerado o maior estudo contínuo (ocorre anualmente) sobre a dinâmica empreendedora. O GEM 2018 contou com a participação de 49 países, incluindo, desde 2010, o Brasil. A análise dos resultados do relatório GEM no Brasil (IBQP-SEBRAE-UFPR, 2018) por gênero mostra oscilação no crescimento do empreendedorismo feminino a partir de 2015, devido a desaceleração da economia (IBQP, 2019), mas numa perspectiva mais ampla, sustenta o crescimento da participação feminina. Estes dados, no entanto, podem não refletir a condição do auto emprego, entre outras razões, pelas diferenças no que se refere aos conceitos de auto emprego e empreendedorismo e em como eles estão relacionados. $\mathrm{O}$ conceito de auto emprego tem aparecido na literatura sociológica vinculado à condição das mulheres que são mães e têm baixa posição socioeconômica.

Um argumento comum encontrado na literatura sociológica defende que muitas das mulheres que são mães e têm baixa escolaridade tendem a buscar o auto emprego não profissionalizado (MOULTON; SCOTT, 2016; CAVENAGHI; ALVES, 2018). E que a condição de auto emprego feminino também tem crescido (CAVENAGHI; ALVES, 2018). Haveria relação entre o crescimento do número de mulheres chefes de família e o crescimento de mulheres empreendedoras e em condição de auto emprego? Qual a diferença entre a situação da mulher empreendedora e da mulher em condição de auto emprego?

Para responder a estas questões de pesquisa, inicialmente seria importante esclarecer o que a literatura nas disciplinas da sociologia, psicologia social e administração indicam em termos das diferenças nos conceitos de empreendedorismo e de auto emprego. Por exemplo, se existem diferenças entre elas.

Quando se busca a relação entre mulheres chefes de família e auto emprego, aparece a condição de mulher empreendedora vinculada a chefia feminina ou a condição da mulher no mercado de trabalho. $O$ que sugere que, se pesquisada a relação entre mulheres chefes de família e auto emprego, o termo empreendedorismo aparecerá com regularidade.

A sociologia e psicologia social são áreas que têm discutido a mudança da condição da mulher no mercado de trabalho e na estrutura social da família (SCASE; GOFFEE, 1988; MOULTON; SCOTT, 2016). E a administração tem discutido a realidade e desafios do empreendedorismo com mais intensidade (HUEFNER; HUNT, 1994; PEREDO; MCLEAN, 2006), portanto, para pesquisar a relação entre mulheres chefes de família e auto emprego, um bom ponto de partida seria entender o que a literatura indica em termos de diferenças e semelhanças entre os conceitos de empreendedorismo e auto emprego. Em que disciplinas os conceitos de auto emprego e empreendedorismo tendem a aparecer com mais regularidade e como eles estão relacionados?

\section{Referencial Teórico}

A partir da pergunta de pesquisa, formulou-se as seguintes hipóteses de pesquisa: hipótese geral - compatível com as afinidades teóricas de cada área, pode-se dizer que o conceito de auto emprego tende a aparecer com mais regularidade nas áreas de psicologia social e sociologia enquanto o de empreendedorismo tende a aparecer mais na área da administração. 
Trata-se de hipótese inspirada pela teoria da escolha racional (HECHTER; KANAZAWA, 1999; SANDERSON, 2001), que defende que os atores sociais fazem escolhas racionais relacionadas aos significados que eles dão aos seus objetivos e não em relação às metas em si mesmas. Ou seja, os pesquisadores seguirão as tradições de pesquisa de suas áreas, que envolvem entre outras coisas, conceitos e tendências teóricas e metodológicas. Sendo assim, o conceito de auto emprego, embora hoje esteja pouco presente na literatura sociológica e da psicologia social, já esteve presente nos anos de 1980 e, portanto, tende ainda a se fazer presente na discussão na condição da mulher no mercado de trabalho e do crescimento do número de mulheres chefes de família., daí a hipótese 1 - os conceitos de auto emprego e empreendedorismo tenderão a aparecer mais separados do que interligados.

Conforme a teoria da escolha racional, embora possam aparecer juntos, os pesquisadores tenderão a colocar ênfase nos conceitos mais vinculados a suas disciplinas de atuação e isso constitui uma escolha que se pode chamar de racional.

A moderna teoria da escolha racional (RAT - Rational Action Theory também conhecida como Rational Choice Theory) representa um desenvolvimento e extensão da teoria da troca (SANDERSON, 2001). Foi e tem sido desenvolvida mais extensivamente por James Coleman e Michael Hechter e seus estudantes e colegas (HECHTER; KANAZAWA, 1999; SANDERSON, 2001). A RAT está fundamentada no mesmo princípio da teoria da troca: as pessoas orientam seus comportamentos em direção à maximização de recompensas e minimização de custos e as instituições das sociedades são agregadas resultantes das escolhas dos indivíduos, mas a teoria da escolha racional é consideravelmente mais sofisticada.

Para a RAT, o comportamento social é o produto da interação de atores que agem propositalmente ou intencionalmente, de acordo com uma hierarquia de preferências. Os atores esforçam-se para realizar essas preferências com um custo mínimo. Atores são calculadores racionais de benefícios e custos. Atores sociais fazem escolhas racionais relacionadas aos significados que eles dão aos seus objetivos e não em relação às metas em si mesmas. Ou seja, valores ou crenças do ator social podem ser decisivas em suas escolhas. Um pesquisador de uma determinada área tende a usar os conceitos da área de conhecimento em que foi socializado. Suas escolhas sofrem restrições que ele leva em consideração.

Os cálculos racionais feitos pelos atores sociais estão sujeitos a pelo menos dois tipos de restrições. O primeiro tipo de restrições é a escassez de recursos. Os indivíduos enfrentam custos de oportunidade, ou custos associados aos precedentes cursos de ação. Eles enfrentam restrições institucionais que agem como sanções positivas ou negativas sobre o benefício líquido de qualquer curso de ação (HECHTER; KANAZAWA, 1999; SANDERSON, 2001; ELSTER, 2007).

Quando escreve um artigo, um pesquisador localiza-se dentro de um determinado território disciplinar ou interdisciplinar, mas orienta-se por conceitos e normas relativas ao seu campo de estudo. Os próprios periódicos impõem restrições para que um artigo seja aceito.

A hipótese geral desse trabalho defende que o conceito de auto emprego tende a aparecer com mais regularidade nas áreas de psicologia social e sociologia enquanto o de empreendedorismo tende a aparecer mais na área da administração.

Ou seja, postula que o conceito de auto emprego, por ser familiar a certas tradições de pesquisa sociológica, será mais encontrado em periódicos indexados pela base de dados sociológica, no caso o PROQUEST. Pelas mesmas razões, postula que o conceito 
de empreendedorismo será mais encontrado em periódicos indexados pelas bases de dados da administração, no caso o SCOPUS.

A hipótese de que os conceitos de auto emprego e empreendedorismo tenderão a aparecer mais separados do que interligados tem inspiração da teoria da escolha racional no sentido de que os campos disciplinares tendem a zelar por seus conceitos considerados importantes e, embora não seja raro, é incomum que pesquisadores utilizem conceitos de outros campos disciplinares. Trata-se de um tipo de restrição institucional.

\section{Procedimentos Metodológicos}

Para sustentar as hipóteses formuladas, realizou-se um processo de revisão sistemática na literatura das áreas de administração, psicologia social e sociologia. Define-se como revisão sistemática, um processo de revisão de literatura que é replicável, científico e transparente e que visa minimizar o viés por meio de pesquisas exaustivas na literatura de estudos publicados e não publicados e consegue fornecer uma trilha de auditoria da decisão, procedimentos e conclusões do revisor (BRYMAN, 2016).

O objetivo da pesquisa foi investigar os conceitos de auto emprego que aparecem vinculados à condição de mulheres chefes de família. A pesquisa foi realizada no mês de maio de 2019. Os recursos e estratégias para busca e seleção de estudos foram definidos e selecionados com base em quatro itens fundamentais:

(1) Fontes de busca: base de dados eletrônicas de sociologia (PROQUEST), psicologia (JSTOR) biblioteca de teses e dissertações e administração (SCOPUS).

(2) Idioma: Inglês e português.

(3) Palavras-chaves: "auto emprego"; "mulheres chefes de família"; "mulheres chefes de família e auto emprego"; "self employment"; woman AND "self employment"; "working women" AND "Self-employment"; "working women AND heads of family".

(4) Período de publicação: 2008 a 2018.

Alguns critérios e procedimentos foram estabelecidos para seleção dos estudos.

Critérios de inclusão:

1. Artigos publicados dentro do intervalo de 10 (dez) anos.

2. Artigos que buscam respostas para perguntas pré-definidas.

3. Títulos e resumos que trazem termos e conceitos de mulheres, auto emprego e chefia de família.

4. Artigos da área de administração, sociologia e psicologia social. Com uma observação: artigos publicados na base de dados de alguma das três áreas que seja da economia serão considerados na medida em que sejam compatíveis com o tema buscado.

5. Artigos que estejam disponíveis na íntegra.

Critérios de exclusão:

1. Artigos publicados fora do intervalo estabelecido e que não estejam na integra;

2. Artigos repetidos nas buscas;

3. Artigos que não fazem referências ao assunto foco;

4. Artigos que não seja nas linguagens estabelecidas; 
5. Artigos que não são da área desejada: sociologia e psicologia social e administração. Com uma observação: artigos publicados na base de dados de alguma das três áreas que seja da economia serão considerados na medida em que sejam compatíveis com o tema buscado.

A revisão sistemática foi realizada segundo os cinco passos de Bryman (2016):

1. Definir objetivo (s) e escopo da revisão - declaração explícita sobre o objetivo da revisão, questão de pesquisa, palavras-chave.

2. Buscar estudos relevantes para o escopo da revisão - a busca é baseada sobre palavras-chaves e termos que foram definidos no passo 1.

3. Avaliar a relevância de cada estudo para a questão de pesquisa - a partir da análise do título e resumo e depois da leitura do próprio artigo visando identificar o alinhamento do artigo a questão de pesquisa.

4. Avaliar a qualidade dos artigos encontrados no passo 3 - precisa ser feito anteriormente um checklist para analisar a qualidade do trabalho que pode variar de acordo com o escopo da revisão (tais como os critérios de inclusão e critérios de exclusão).

5. Extrair os resultados de cada artigo e sintetizá-los - criar um meio de sintetizar dados relevantes de cada trabalho. Pode ser usada a síntese narrativa, síntese de meta-análise, síntese meta-etnográfica.

\section{Análise dos Resultados}

A primeira etapa, conforme Bryman (2016), com todas as strings de busca, chegou à Tabela 1.

Tabela 1. Strings de busca, base de dados e total de artigos encontrados

\begin{tabular}{|c|c|c|c|c|c|}
\hline ID & String & PROQUEST & JSTOR & SCOPUS & Total \\
\hline 1 & self employment & 3 & 1 & 4285 & 4 \\
\hline 2 & head of household women NOT child & 0 & 12 & 1 & 13 \\
\hline 3 & $\begin{array}{c}\text { self employment AND head of household } \\
\text { women }\end{array}$ & 0 & 0 & 0 & 0 \\
\hline 4 & working women AND self employment & 108 & 0 & 36 & 144 \\
\hline 5 & working women AND heads of family & 3 & 71 & 0 & 74 \\
\hline 6 & women AND self employment NOT child & 390 & 19 & 1994 & 409 \\
\hline & & & & Total & 644 \\
\hline
\end{tabular}

Fonte. Dados da pesquisa (2019)

A partir do total de 644 artigos encontrados na primeira etapa da RS, a segunda etapa (BRYMAN, 2016), excluiu 584 artigos considerando três critérios de exclusão: (1) título ou resumo (abstract) não relevantes/não contém informações úteis para o objetivo da pesquisa; (2) artigo não estava disponível (3) área de estudo distinta de psicologia, sociologia ou administração. E, por fim, dos 60 artigos selecionados, 20 artigos repetidos foram excluídos, restando 40 artigos para a terceira etapa (Tabela 2). 
Tabela 2. Relação dos artigos selecionados na etapa 2

\begin{tabular}{|c|c|c|}
\hline String & SCOPUS & \\
\hline Artigo & Periódico & Ano \\
\hline $\begin{array}{l}\text { A model for the training in entrepreneurship of } \\
\text { women heads of households located in the } \\
\text { Municipality of Duitama, Colombia. Serrano } \\
\text { Amado, A.M. Montoya Restrepo, L.A. Puentes } \\
\text { Montañez, G.A. }\end{array}$ & Espacios & 2017 \\
\hline \begin{tabular}{|l|l|}
4 & Base $\mathbf{u}$ \\
\end{tabular} & PROQUEST & \\
\hline Artigo & Periódico & Ano \\
\hline $\begin{array}{l}\text { Workers on the Border between Employment and } \\
\text { Self-employment. Muehlberger, Ulrike; Pasqua, } \\
\text { Silvia }\end{array}$ & Review of Social Economy & 2009 \\
\hline $\begin{array}{l}\text { Self-Employment, Work-Family Fit and Mental } \\
\text { Health among Female Workers. Tuttle, Robert; Garr, } \\
\text { Michael }\end{array}$ & $\begin{array}{l}\text { Journal of Family and } \\
\text { Economic Issues }\end{array}$ & 2009 \\
\hline $\begin{array}{llll}\text { Self Employment of Women: Preference or } \\
\text { Compulsion. N., Neetha }\end{array}$ & Social Change & 2010 \\
\hline $\begin{array}{l}\text { Gender discrimination and self-employment } \\
\text { dynamics in Europe. Williams, Donald R }\end{array}$ & $\begin{array}{l}\text { The Journal of Socio- } \\
\text { Economics }\end{array}$ & 2012 \\
\hline $\begin{array}{l}\text { Time triage: Exploring the temporal strategies that } \\
\text { support entrepreneurship and motherhood. Carrigan, } \\
\text { Marylyn; Duberley, Joanne }\end{array}$ & Time \& Society & 2013 \\
\hline $\begin{array}{l}\text { Self-Employment and Women: an Insider's } \\
\text { Testimonies. Shah, Nasreen Aslam }\end{array}$ & $\begin{array}{l}\text { Pakistan Journal of Women's } \\
\text { Studies }\end{array}$ & 2014 \\
\hline $\begin{array}{l}\text { Who's the Boss? Explaining Gender Inequality in } \\
\text { Entrepreneurial Teams. Yang, Tiantian; Aldrich, } \\
\text { Howard E }\end{array}$ & $\begin{array}{ll}\text { American } & \text { Sociological } \\
\text { Review } & \end{array}$ & 2014 \\
\hline $\begin{array}{l}\text { Marriage, Children, and Self-Employment Earnings: } \\
\text { An Analysis of Self-Employed Women in the US. } \\
\text { Marshall, Maria I; Flaig, Anna }\end{array}$ & $\begin{array}{l}\text { Journal of Family and } \\
\text { Economic Issues }\end{array}$ & 2014 \\
\hline $\begin{array}{l}\text { Women and Self-employment in Post-socialist Rural } \\
\text { China: Side Job, Individual Career or Family } \\
\text { Venture. Song, Jing }\end{array}$ & The China Quarterly & 2015 \\
\hline $\begin{array}{l}\text { From Emancipation through Employment to } \\
\text { Emancipation through Entrepreneurship: An } \\
\text { Analysis of the Special Labor Market Initiatives } \\
\text { (BRYT) and Tax Deduction for Domestic Services } \\
\text { (RUT) in Sweden. Kvist, Elin; Overud, Johanna }\end{array}$ & $\begin{array}{l}\text { Nordic Journal of Working } \\
\text { Life Studies }\end{array}$ & 2015 \\
\hline $\begin{array}{l}\text { Women's Short-Term Employment Trajectories } \\
\text { Following Birth: Patterns, Determinants, and } \\
\text { Variations by Race/Ethnicity and Nativity. Lu, Yao; } \\
\text { Wang, Julia Shu-huah; Han, Wen-jui }\end{array}$ & Demography & 2017 \\
\hline $\begin{array}{l}\text { Formalizing women entrepreneurs in Kathmandu, } \\
\text { Nepal. Thapa Karki Shova; Xheneti Mirela }\end{array}$ & $\begin{array}{l}\text { The International Journal of } \\
\text { Sociology and Social Policy }\end{array}$ & 2018 \\
\hline $\begin{array}{l}\text { Do American mothers use self-employment as a } \\
\text { flexible work alternative? Lim, Katherine }\end{array}$ & $\begin{array}{l}\text { Review of Economics of the } \\
\text { Household }\end{array}$ & 2018 \\
\hline String & SCOPUS & \\
\hline Artigo & Periódico & Ano \\
\hline $\begin{array}{l}\text { Opting out: professional women develop reflexive } \\
\text { agency. Biese, I., Choroszewicz, M. }\end{array}$ & 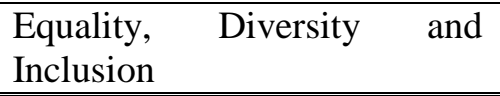 & 2019 \\
\hline
\end{tabular}




\begin{tabular}{|c|c|c|}
\hline $\begin{array}{l}\text { Domestic economic and social conditions } \\
\text { empowering female entrepreneurship. Ribes-Giner, } \\
\text { G., Moya-Clemente, I., Cervelló-Royo, R., Perello- } \\
\text { Marin, M.R. }\end{array}$ & Journal of Business Research & 2018 \\
\hline $\begin{array}{l}\text { Self-employment and the paradox of the contented } \\
\text { female worker. Bender, K.A., Roche, K. }\end{array}$ & Small Business Economics & 2016 \\
\hline $\begin{array}{l}\text { Gender and entrepreneurship: An annotated } \\
\text { bibliography. Link, A.N., Strong, D.R. }\end{array}$ & $\begin{array}{l}\text { Foundations and Trends in } \\
\text { Entrepreneurship }\end{array}$ & 2016 \\
\hline $\begin{array}{l}\text { Entrepreneurial motivations of women: Evidence } \\
\text { from the United Arab Emirates. Tlaiss, H.A. }\end{array}$ & $\begin{array}{lr}\text { International Small Business } \\
\text { Journal: } \quad \text { Researching } \\
\text { Entrepreneurship }\end{array}$ & 2015 \\
\hline $\begin{array}{l}\text { An examination of how husbands, as key } \\
\text { stakeholders, impact the success of women } \\
\text { entrepreneurs. Nikina, A., Shelton, L.M., Leloarne, } \\
\text { S. }\end{array}$ & $\begin{array}{l}\text { Journal of Small Business and } \\
\text { Enterprise Development }\end{array}$ & 2015 \\
\hline $\begin{array}{l}\text { Stitching toward empowerment: A case study of } \\
\text { Tabiro Ladies' Club. Dol, J., Hambly Odame, H. }\end{array}$ & $\begin{array}{l}\text { Journal of Co-operative } \\
\text { Organization and Management }\end{array}$ & 2013 \\
\hline $\begin{array}{l}\text { Gender and work-life balance: A phenomenological } \\
\text { study of women entrepreneurs in Pakistan. Rehman, } \\
\text { S., Roomi, M.A. }\end{array}$ & $\begin{array}{l}\text { Journal of Small Business and } \\
\text { Enterprise Development }\end{array}$ & 2012 \\
\hline $\begin{array}{l}\text { Female entrepreneurship in China: Opportunity- or } \\
\text { necessity-based? Hernandez, L., Nunn, N., } \\
\text { Warnecke, T. }\end{array}$ & $\begin{array}{l}\text { International Journal of } \\
\text { Entrepreneurship and Small } \\
\text { Business }\end{array}$ & 2012 \\
\hline $\begin{array}{l}\text { Training women for success: An evaluation of } \\
\text { entrepreneurship training programs in vermont, } \\
\text { USA. Bauer, K. }\end{array}$ & $\begin{array}{l}\text { Journal of Entrepreneurship } \\
\text { Education }\end{array}$ & 2011 \\
\hline $\begin{array}{l}\text { Constraints and opportunities facing women } \\
\text { entrepreneurs in developing countries: A relational } \\
\text { perspective. Jamali, D. }\end{array}$ & $\begin{array}{l}\text { Gender in Management: An } \\
\text { International Journal }\end{array}$ & 2009 \\
\hline \begin{tabular}{l|l|l} 
String & 6 & Base u \\
\end{tabular} & PROQUEST & \\
\hline Artigo & Periódico & Ano \\
\hline $\begin{array}{l}\text { Women's Experiences of Micro-Enterprise: Contexts } \\
\text { and Meanings. Strier, Roni; Abdeen, Ziad }\end{array}$ & $\begin{array}{lll}\text { Sex Roles: a Journal of } \\
\text { Research }\end{array}$ & 2009 \\
\hline $\begin{array}{l}\text { Incentives to self-employment decision in Sweden. } \\
\text { Vejsiu, Altin }\end{array}$ & $\begin{array}{l}\text { International Review of } \\
\text { Applied Economics }\end{array}$ & 2011 \\
\hline $\begin{array}{l}\text { A semiparametric analysis of the rising breadwinner } \\
\text { role of women in the UK. Soobedar, Zeenat }\end{array}$ & $\begin{array}{l}\text { Review of Economics of the } \\
\text { Household }\end{array}$ & 2011 \\
\hline $\begin{array}{l}\text { Gendered Paths: Why Women Lag Behind Men in } \\
\text { Small Business Success. Loscocco, Karyn; Bird, } \\
\text { Sharon R }\end{array}$ & Work and Occupations & 2012 \\
\hline $\begin{array}{l}\text { Women's Entry into Self-employment in Urban } \\
\text { China: The Role of Family in Creating Gendered } \\
\text { Mobility Patterns. Zhang, Qian Forrest; Pan, Zi }\end{array}$ & World Development & 2012 \\
\hline $\begin{array}{l}\text { Filling the Gap? Female Entrepreneurs in } \\
\text { Szeklerland, Romania. Gergely, Orsolya }\end{array}$ & $\begin{array}{l}\text { Generos. Multidisciplinary } \\
\text { Journal of Gender Studies }\end{array}$ & 2013 \\
\hline $\begin{array}{l}\text { 'The Best Time is Now!': The Temporal and Spatial } \\
\text { Dynamics of Women Opting in to Self-Employment. } \\
\text { McKie, Linda; Biese, Ingrid; Jyrkinen, Marjut }\end{array}$ & $\begin{array}{l}\text { Gender, Work } \\
\text { Organization }\end{array}$ & 2013 \\
\hline $\begin{array}{l}\text { Reconciling gender differences in the returns to } \\
\text { education in self-employment: Does occupation } \\
\text { matter? Roche, Kristen }\end{array}$ & $\begin{array}{l}\text { The Journal of Socio- } \\
\text { Economics }\end{array}$ & 2013 \\
\hline
\end{tabular}




\begin{tabular}{|c|c|c|}
\hline $\begin{array}{l}\text { Children and family: A barrier or an incentive to } \\
\text { female self-employment in Norway? Ronsen, Marit }\end{array}$ & International Labour Review & 2014 \\
\hline $\begin{array}{l}\text { The Self-Employment of Men and Women: What are } \\
\text { their Motivations? Allen, W David; Curington, } \\
\text { William P }\end{array}$ & Journal of Labor Research & 2014 \\
\hline $\begin{array}{l}\text { Gendered division of housework in Germany - The } \\
\text { role of self-employment, relative resources and } \\
\text { gender role orientation. König, Stefanie; Langhauser, } \\
\text { Marc }\end{array}$ & $\begin{array}{l}\text { Zeitschrift für } \text { Familien } \\
\text { forschung }\end{array}$ & 2016 \\
\hline $\begin{array}{l}\text { Entrepreneurship and Socioeconomic Indicators in } \\
\text { Latin America. Amorós, José E.; Borraz, Fernando; } \\
\text { Veiga, Leonardo }\end{array}$ & $\begin{array}{l}\text { Latin American Research } \\
\text { Review }\end{array}$ & 2016 \\
\hline $\begin{array}{l}\text { Barriers to women entrepreneurship. Different } \\
\text { methods, different results? Tur-porcar, Ana; Mas-tur, } \\
\text { Alicia; Belso, José Antonio }\end{array}$ & Quality and Quantity & 2017 \\
\hline $\begin{array}{l}\text { 'Is It Entrepreneurship, or Is It Survival?': Gender, } \\
\text { Community, and Innovation in Boston's Black } \\
\text { Immigrant Micro-Enterprise Spaces. Ping-Ann Addo }\end{array}$ & Societies & 2017 \\
\hline String & JSTOR & \\
\hline Artigo & Periódico & Ano \\
\hline $\begin{array}{l}\text { Gender and Entrepreneurship as a Career Choice: Do } \\
\text { Self-assessments of Ability Matter? Sarah Thébaud }\end{array}$ & $\begin{array}{l}\text { Social Psychology Quarterly, } \\
\text { Vol. 73, No. } 3 \text { (September } \\
\text { 2010), pp. 288-304 }\end{array}$ & 2010 \\
\hline
\end{tabular}

Fonte. Dados da pesquisa (2019)

$\mathrm{Na}$ terceira etapa, cinco artigos foram descartados por não se enquadrarem no protocolo de pesquisa. Portanto, restaram 35 artigos. Quantidade que se manteve nas etapas 4 e 5. Dos 35 artigos, PROQUEST forneceu 25, SCOPUS 09 e JSTOR 01. Estes foram organizados conforme sua área disciplinar apresentados na Tabela 3.

Tabela 3. Áreas disciplinares dos artigos encontrados em PROQUEST, SCOPUS e JSTOR

\begin{tabular}{|c|c|c|c|}
\hline & PROQUEST & SCOPUS & JSTOR \\
\hline Administração & - & 06 & - \\
\hline Demografia & 01 & - & - \\
\hline Economia & 06 & 02 & - \\
\hline Interdisciplinar & 10 & 01 & - \\
\hline Psicologia Social & - & - & 01 \\
\hline Sociologia & 06 & - & - \\
\hline Socioeconomia & 02 & - & - \\
\hline Total & 25 & 09 & 01 \\
\hline
\end{tabular}

Fonte. Dados da pesquisa (2019)

A Tabela 3 mostra que a base de dados da sociologia (PROQUEST) indexou quantidades iguais de artigos nas áreas da sociologia e economia e mais ainda nas áreas interdisciplinares, basicamente ciências sociais. Mas, não indexou nada na área da administração.

A psicologia social só forneceu um artigo e, portanto, não correspondeu às expectativas existentes na hipótese geral e H1. Ou seja, parece que a discussão sobre a relação entre mulheres chefe de família e auto emprego não é um tema considerado 
importante. Na administração, a maioria dos artigos indexados pertence à própria área e dois artigos de economia.

Conforme foi proposto no protocolo da revisão sistemática, artigos vinculados a área da economia apareceram tanto no PROQUEST quanto no SCOPUS, o que sugere que a relação entre mulheres chefes de família e auto emprego é um tema também abordado pelos economistas.

A presença de artigos da economia se dá porque os artigos discutem a relação entre mulheres chefes de família e auto emprego. Em geral, as abordagens dos economistas têm a preocupação de discutir problemas relacionados ao desemprego em que o auto emprego e o empreendedorismo aparecem como alternativas.

A área de psicologia social não correspondeu às expectativas. Pode ser uma restrição relacionada à base de dados ou um dado da realidade da área, a temática não está na agenda de pesquisa da área. Os trinta e cinco artigos abordam o auto emprego, empreendedorismo, juntos ou separados. Para entender como isso está organizado na amostra selecionada, organizamos a Tabela 4.

Tabela 4. Como os artigos relacionam os conceitos de auto emprego e empreendedorismo

\begin{tabular}{|l|c|c|c|}
\hline & PROQUEST & SCOPUS & JSTOR \\
\hline Auto emprego e empreendedorismo como conceitos afins & 03 & 01 & - \\
\hline Enfase no conceito de Empreendedorismo & 04 & 06 & 01 \\
\hline Enfoca apenas conceito de auto emprego & 06 & 01 & - \\
\hline $\begin{array}{l}\text { Auto emprego e empreendedorismo como conceitos } \\
\text { diferentes }\end{array}$ & 10 & 01 & - \\
\hline Conceito de auto emprego inclui empreendedorismo & 02 & - & - \\
\hline Total & 25 & 09 & 01 \\
\hline
\end{tabular}

Mais de $60 \%$ dos artigos $(66,66 \%)$ encontrados pela base de dados Scopus, da administração, colocam ênfase no conceito de empreendedorismo. Este dado é compatível com a hipótese geral que afirma que é possível dizer que o conceito de auto emprego tende a aparecer com mais regularidade nas áreas de psicologia social e sociologia enquanto o de empreendedorismo tende a aparecer mais na área da administração.

Nos artigos da base de dados da sociologia, $24 \%$ enfocam apenas o conceito de auto emprego e $40 \%$ apresentam o conceito de auto emprego e empreendedorismo como conceitos diferentes. Ou seja, o conceito de auto emprego apareceu mais vezes que a ênfase dada apenas ao conceito de empreendedorismo (16\%).

A hipótese 1 (H1), que diz que os conceitos de auto emprego e empreendedorismo tenderão a aparecer mais separados do que interligados parece muito geral para os dados. A questão pertinente seria: interligados como? Na base de dados da sociologia, em $40 \%$ dos artigos menciona-se os dois conceitos, mas eles são considerados diferentes. Em alguns artigos eles não deixam de ter algum tipo de ligação. De maneira geral, o conceito de auto emprego tende a ser aplicado a indivíduos que trabalham para si mesmos, ou seja, eles não têm um patrão. Geralmente os artigos apresentam como exemplos empíricos o trabalho de autônomos não profissionalizados ou semiprofissionalizados.

Por outro lado, o conceito de empreendedorismo tende a ser aplicado ao indivíduo que trabalha para si mesmo, mas é proprietário de um negócio (uma empresa). Diferentemente do indivíduo do auto emprego que não é proprietário do negócio. Esta é uma das distinções que aparece nos artigos. 
Em relação a interligação entre os conceitos de auto emprego e empreendedorismo, alguns artigos consideram que o conceito de auto emprego inclui o conceito de empreendedorismo enquanto outros parecem sugerir o contrário, ou seja, que o conceito de empreendedorismo engloba o conceito de auto emprego porque coloca ênfase na questão do risco que o trabalhador se dispõe a enfrentar. Nesse sentido, o auto emprego seria o tipo mais simples de empreendedorismo.

Para entender melhor as nuances dessas diferenças, uma análise de conteúdo dos artigos poderá nos ajudar a refinar as categorias de auto emprego e empreendedorismo.

\section{Considerações Finais}

A discussão sobre auto emprego tem aparecido vinculada à condição de imigrantes, minorias, idosos e de mulheres casadas com filhos. O conceito de empreendedorismo aparece como um complemento ao conceito de auto emprego e viceversa. Auto emprego é a forma mais simples de empreendedorismo? O conceito de auto emprego engloba o conceito de empreendedorismo? São conceitos afins? Pela amostra dos trinta e cinco artigos selecionados não existe consenso. Não se pode afirmar que não existe consenso dentro das disciplinas, mas pode-se afirmar que não existe consenso entre elas. Uma verificação em mais bases de dados dentro de uma mesma disciplina seria interessante nesse sentido.

Em relação à comparação entre as disciplinas, investigações em mais bases de dados seriam importantes. Novas pesquisas, por exemplo, usando análise de conteúdo podem ser realizadas para refinar a compreensão dos conceitos de auto emprego e empreendedorismo nas disciplinas de sociologia e administração. E uma boa sugestão seria incluir a área da economia, que discute os dois conceitos, o que a coloca em uma posição intermediária entre a sociologia e a administração.

Outra frente de trabalho importante seria desenvolver pesquisas empíricas que possam testar a validade dos diversos conceitos de auto emprego e empreendedorismo.

\section{Referências}

BRYMAN, A. Social Research Methods. 5ª ed. Oxford, 2016.

CAVENAGHI, S.; ALVES, J. E. D. Mulheres Chefes de Família no Brasil: avanços e desafios. Rio de Janeiro: Escola Nacional de Seguros - CPES, 2018.

ELSTER, J. La Explicacion del Comportamiento Social. Barcelona: Gedisa Editorial, 2007.

GEM. Global Entrepreneurship Monitor - Brasil. Empreendedorismo no Brasil: 2015. (Coordenação de Simara M. de S. S. Greco) Macedo, M. de M. et al. Curitiba: IBQP, 2014.

HECHTER, M.; KANAZAWA, S. Sociological Rational Choice Theory. Annual Review of Sociology, v.23. pp. 191-214, 1999. 
HUEFNER, J.C.; HUNT, H.K. Broadening the concept of entrepreneurship: comparing business and consumer entrepreneurs. Entrepreneurship Theory and Practice, Spring 1994.

IBQP. GEM 2018: Análise dos resultados por gênero. (relatório técnico). 2019.

IBQP-SEBRAE-UFPR. Empreendedorismo no Brasil: relatório executivo 2018. GEM: Global Entrepreneurship Monitor. 2018.

KALlEBERG, A. L. Nonstandard Employment Relations: part-time, temporary and contract work. Annual Reviews of Sociology. Vol. 26. pp. 341-365, 2000.

MOULTON, J. G.; SCOTT, J. C. Opportunity or Necessity? Disaggregating SelfEmployment and Entry at Older Ages. Social Forces, v. 94, issue 4. pp. 1539-1566, June 2016.

PEREDO, A.M.; MCLEAN, M. Social entrepreneurship: A critical review of concept. Journal of World Business, 41, 2006.

SANDERSON, S. K. The Evolution of Human Sociality: a Darwinian conflict perspective. Oxford: Rowman \& Littlefield Publishers, Inc., 2001.

SCASE, R.; GOFFEE, R. The Real World of the Small Business Owner. New York: Routledge, 1988. 